\title{
Optimalisasi Biaya dan Waktu Pelaksanaan Proyek Pembangunan Kantor Dinas Peternakan Kabupaten Bone Bolango dengan Metode Least Cost Analysis
}

\author{
Fikri A. Paramata 1), Arfan Utiarahman 2) \\ 1),2) Jurusan Teknik Sipil, Fakultas Teknik, Universitas Negeri Gorontalo. \\ email: fikri.paramata@gmail.com
}

\begin{abstract}
Abstrak
Pelaksanaan proyek konstruksi memerlukan adanya manajemen proyek yang terorganisir, baik dari segi perencanaan, pengorganisasian, pelaksanaan dan pengendalian. Hal ini dimaksudkan agar dapat meningkatkan sistem pengelolaan proyek yang baik dan terintegrasi. Penelitian ini bertujuan untuk menentukan jaringan kerja, menganalisis durasi dan biaya optimal pelaksaan proyek pembangunan gedung Kantor Dinas Peternakan Kabupaten Bone Bolango. Penelitian ini menggunakan metode Least Cost Analysis untuk memperoleh waktu dan biaya yang optimal. Penjadwalan menggunakan metode CPM (critical path method) atau metode jalur kritis. Pekerjaan terpilih yang berada pada lintasan kritis selanjutnya di crash program dengan cara menambahkan jumlah pekerja dan jumlah jam kerja (lembur) pada pekerjaan yang dipercepat. Hasil penelitian menunujukkan durasi optimal pekerjaan 168 hari kerja dari durasi normal 180 hari kerja, terjadi efisiensi waktu sebesar $6,67 \%$. Biaya optimal ditentukan sebesar Rp. 1.604.248.723 terjadi kenaikan biaya akibat percepatan sebesar Rp. 7.273.214.
\end{abstract}

Kata Kunci: Optimalisasi, Least Cost Analysis, Metode CPM, Crash Program.

\begin{abstract}
The implementation of construction project needs an organized project management whether in planning organizing implementing, and controlling, This is to ensure a good and integrated project management system. This research aims al determining work network, analyzing duration and optimum budget for implementation construction of Animal Husbandry Department Office of Bone Bolango District This research applies Least Cost Analysis method to gain optimum time and budget. The scheduling uses CPM (Critical Path Method). The chosen work is in critical line then crash programmed by adding the number of workers and number of working hours on accelerated working The research shows that working optimum duration is 168 working hours out of normal duration namely 180 working hours, there is a $6,67 \%$ of time efficiency. The optimum determined budget is Rp. 1.604.248.723. There is an increase of budget caused by acceleration as much as Rp. 7.273.214.
\end{abstract}

Keywords: Optimization, Least Cost Analysis. CPM, Crash Programs

\section{Pendahuluan}

Kabupaten Bone Bolango merupakan salah satu Kabupaten yang sedang berkembang di Provinsi Gorontalo. Hal ini dapat dilihat dari pembangunan infrastruktur baik jalan dan gedung-gedung perkantoran, salah satunya adalah pembangunan Gedung Kantor dinas Peternakan Kabupaten Bone Bolango, proyek ini terdiri dari tiga pekerjaan besar yaitu pekerjaan pleriminaries dan site work, pekerjaan gedung dan pekerjaan pembersihan akhir. Proyek konstruksi pembangunan gedung Dinas Peternakan Kabupaten Bone Bolango dalam penyelesaiannya tentunya menemukan 
berbagai macam kendala sehingga diperlukan adanya manajemen proyek yang terorganisir.

Proyek konstruksi juga memerlukan adanya penjadwalan, sehingga semua pekerjaan yang dilaksanakan dapat selesai sesuai waktu yang telah ditentukan. Penjadwalan sangat berpengaruh pada proses percepatan proyek, baik proyek yang berjalan normal atau proyek yang mengalami keterlambatan. Proyek yang mengalami percepatan akan membutuhkan biaya yang besar begitu pula sebaliknya apabila proyek terjadi keterlambatan maka akan membutuhkan biaya yang besar pula. Untuk mengantisipasinya kita dapat mengoptimalkan waktu dan biayanya.Adapun tujuan dari penelitian ini adalah untuk menentukan jaringan kerja, menganalisis durasi optimal dan menganalisis biaya optimal akibat percepatan durasi proyek pembangunan gedung kantor dinas peternakan kabupaten bone bolango.

Penelitian ini diharapkan dapat memberikan masukan kepada instansi atau perusahaan yang terlibat dalam proyek konstruksi sehingganya dapat menghasilkan suatu produk konstruksi yang memiliki waktu dan biaya yang optimal.

\section{Metode}

\section{a. Penentuan Objek Studi}

Yang menjadi objek studi adalah optimalisasi biaya dan waktu pelaksanaan proyek, dimana studi kasus diambil pada proyek pembangunan gedung Kantor Dinas Peternakan Kabupaten Bone Bolango.

\section{b. Studi Literatur}

Pada tahap ini meliputi studi kepustakaan diantaranya buku-buku dari para ahli dibidang manajemen konstruksi, penelitian sebelumnya dan juga berupa peraturanperaturan pemerintah.

\section{c. Pengumpulan Data}

Data yang dikumpulkan berupa data primer dan data sekunder. Data primer adalah data yang didapatkan langsung dari pihak kontraktor yakni melalui proses wawancara dengan narasumber yang telah dipilih, sedangkan data sekunder adalah data yang dikumpulkan sendiri oleh peneliti dari sumber-sumber yang sudah ada seperti rencana anggaran biaya $(R A B)$ dan data pendukung lainnya.

\section{d. Analisis Data}

Pengolahan data dilakukan dalam beberapa tahap sebagai berikut.

1. Survey pendahuluan dilakukan sebelum melakukan penelitian. survey pendahuluan bertujuan untuk mengetahui kondisi lokasi penelitian.

2. Studi pustaka dilakukan dengan cara mengumpulkan referensi penelitian baik itu dari buku maupun dari penelitian sebelumnya sebagai pedoman dalam 
melaksanakan penelitian nanti, baik itu untuk acuan pengambilan data maupun untuk pengolahan data.

3. Pengumpulan data, adapun data-data yang diperlukan adalah RAB (Rencana Anggaran Biaya), Kurva S, Network Planning dan biaya tidak langsung.

4. Analisis data, melakukan perencanaan dengan menggunakan metode jaringan kerja Critical Path Method atau metode lintasan kritis, setelah didapatkan pekerjaan yang berada pada lintasan kritis kemudian dilanjutkan dengan crash program.

5. Least Cost Analysis, setelah didapatkan biaya dari crash program maka selanjutnya analisis penambahan biaya yakni menambahkan biaya tidak langsung pada total biaya proyek.

6. Analisis data dilakukan dengan cara trial and erorr yakni cara coba-coba maksudnya untuk mendapatkan waktu dan biaya yang optimal, setelah didapatkan waktu dan biaya yang optimal maka dilanjutkan dengan kesimpulan dan.

7. Kesimpulan dan saran diperoleh setelah selesai dalam pengolahan data dan analisis data.

\section{Hasil dan Pembahasan}

\section{Analisis Optimalisasi Biaya dan Waktu}

Optimalisasi biaya dan waktu proyek yakni dengan merencanakan penjadwalan ulang suatu proyek, tentunya dengan mempercepat beberapa item pekerjaan. Mempercepat pekerjaan dapat dilakukan dengan jalan menambah sumber daya yang ada, baik itu pekerja maupun peralatan. Setelah pekerjaan dipercepat maka akan didapatkan pertambahan biaya (cost slope) pekerjaan yang dipercepat.

Adapun tahapan-tahapan dalam mempercepat pelaksanaan proyek sebagai berikut.

1. Perhitungan durasi pekerjaan.

2. Penyususnan jaringan kerja (network planning).

3. Mengidentifikasi jalur kritis dan perhitungan total float kegiatan.

4. Crash program kegiatan yang terpilih.

5. Perhitungan biaya langsung, biaya tidak langsung dan total biaya proyek.

6. Analisis perhitungan biaya dan waktu.

\section{Perhitungan Least Cost Analysis}

Biaya least cost anlysis meliputi biaya langsung (direct cost) dan biaya tidak langsung (indirect cost), jika adanya bonus maka jumlah dari biaya langsung dan biaya tidak langsung harus dikurangi dengan bonus (profit) dari perusahaan. 


\section{1). Perhitungan Biaya Tidak Langsung}

Biaya langsung (Direct cost) merupakan keseluruhan biaya proyek yang berjalan normal. Biaya langsung dapat dilihat pada tabel 1.

Tabel 1. Daftar Biaya Tidak Langsung

\begin{tabular}{|c|c|c|}
\hline No & Jenis Pekerjaan & Biaya \\
\hline \multirow[t]{3}{*}{$\mathbf{I}$} & Preliminaries \& Site Work & \\
\hline & Pekerjaan Persiapan & Rp. $24.830 .800,00$ \\
\hline & Site Work & $300.000,00$ \\
\hline \multirow[t]{11}{*}{ II } & Pekerjaan Gedung Kantor & \\
\hline & Pekerjaan Galian Tanah dan Pondasi & Rp. $131.975 .226,21$ \\
\hline & Pekerjaan beton & Rp. $292.805 .485,87$ \\
\hline & Pekerjaan Dinding, Plesteran dan Acian & Rp. $146.171 .388,71$ \\
\hline & Pekerjaan Atap & Rp. $244.215 .466,19$ \\
\hline & Pekerjaan Plafond & Rp. $107.354 .100,00$ \\
\hline & Pekerjaan Lantai & Rp. $56.872 .355,04$ \\
\hline & Pekerjaan Pintu Dan Jendela & Rp. $123.596 .125,00$ \\
\hline & Pekerjaan Sanitasi & Rp. $60.056 .138,16$ \\
\hline & Pekerjaan Elektrikal & Rp. $44.772 .278,70$ \\
\hline & Pekerjaan Finishing & Rp. $45.964 .735,50$ \\
\hline III & Pekerjaan Akhir & Rp. $\quad 4.500 .000,00$ \\
\hline
\end{tabular}

Sumber: CV. Takabeya Konstruksi (2015)

Total keseluruhan biaya langsung Proyek pembangunan gedung peternakan kabupaten bonebolango sesuai dengan rencana anggaran biaya (RAB) adalah sebesar Rp. 1.411.755.000,00 sudah termasuk PPN 10\%.

\section{2). Perhitungan Crash Program Biaya Proyek}

Perhitungan crash program didasarkan pada kegiatan kritis, berdasarkan hasil analisis network planning pada CPM maka diperoleh kegiatan-kegiatan yang dipilih yaitu kegiatan dengan kode $B, V, W, A D, A l$ dan $A J$.

Kegiatan yang telah dipilih selanjutnya dihitung percepatannnya berdasarkan data biaya langsung yang ada. Salah satu satu contoh perhitungannya adalah sebagai berikut.

\section{3). Pekerjaan Galian Tanah Untuk Pondasi Batu Kali/Belah dan Pondasi Poer}

Percepatan dilakukan dengan cara menambah jumlah pekerja dan jam kerja (Lembur).

Kondisi Normal

Durasi $=7$ hari

Volume $=240,91 \mathrm{M}^{3}$ 
Kapasitas tenaga kerja per $1 \mathrm{M}^{3}$ adalah:

Mandor 0,04 Org/hr @ Rp. 120.000

Pekerja 0,4 Org/hr @ Rp. 80.000

Perhitungan biaya tenaga kerja adalah sebagai berikut.

Kapasitas Pekerja $=\frac{1}{0,4}=2,5$

$=2,5 \mathrm{M}^{3}$ /orang $\cdot$ hari

Jumlah Pekerja $\quad=\frac{240,91}{2,5 \times 7 \text { hari }}=13,76=14$ orang

Jadi upah Pekerja $=14$ orang $\times$ Rp. $80.000=$ Rp. 1.120 .000 perhari

Kapasitas Mandor $=\frac{1}{0,4 / 0,04}=0,1=0,1 \mathrm{M}^{3} /$ orang.hari

Jumlah Mandor $\quad=0,1 \times 14$ orang $=1,4=2$ orang

Jadi upah Mandor $=2$ orang $x$ Rp. $120.000=$ Rp. 240.000 perhari

Jadi upah tenaga kerja durasi normal pekerjaan selama 7 hari adalah:

(Rp. 1.120.000 + Rp. 240.000) x7 hari = Rp. 9.520.000

Selanjutnya pekerjaan ini akan dipercepat 5 hari, untuk perhitungannya persamaan diatas disubtitusi untuk mendapatkan jumlah hari, untuk menentukan jumlah hari ditentukan dengan cara trial and eror atau cara coba-coba. perhitungannya adalah sebagai berikut:

Kondisi percepatan:

Volume $=240,91 \mathrm{M}^{3}$

Perhitungan biaya tenaga kerja adalah sebagai berikut.

Kapasitas Pekerja $=\frac{1}{0,4}=2,5=2,5 \mathrm{M}^{3}$ /orang.hari

Jumlah hari $\quad=\quad \frac{\text { volume }}{\text { kapasitas pekerja } \mathrm{x} \text { jumlah pekerja }}$

Dicoba dengan 19 orang pekerja

Jumlah hari $\quad=\frac{240,91}{2,5 \times 19}=5,07$ hari

Dari perhitungan diatas didapatkan jumlah hari sebesar 5,07 hari, jumlah hari tidak boleh lebih dari jumlah hari yang direncanakan, usahakan mendekati jumlah hari yang direncanakan.

Dicoba dengan 20 orang pekerja

Jumlah hari $\quad=\frac{240,91}{2,5 \times 20}=4,81$ hari

Dicoba dengan 21 orang pekerja

Jumlah hari $\quad=\frac{240,91}{2,5 \times 21}=4,58$ hari

Dari cara coba-coba diatas dapat disimpulkan bahwa semakin banyak pekerja maka semakin sedikit jumlah hari yang diperlukan dalam suatu pekerjaan. Untuk itu 
dipakai pekerja sebanyak 20 orang dengan perhitungan jumlah hari yang paling mendekati angka pembulatan. Selanjutnya dihitung jumlah upah pekerja selama 5 hari. Jadi upah Pekerja $=20$ orang $\times$ Rp. $80.000,00=$ Rp. 1.600 .000 perhari

Kapasitas Mandor $=\frac{1}{0,4 / 0,04}=0,1=0,1 \mathrm{M}^{3}$ /orang.hari

Jumlah Mandor $\quad=0,1 \times 20$ orang $=2=2$ orang

Jadi upah Mandor $=2$ orang $\times$ Rp. $120.000=$ Rp. 240.000perhari

Jadi upah tenaga kerja selama 2 hari durasi pekerjaan dipercepat adalah:

(Rp. 1.600.000 + Rp. 240.000) x 5 hari $=$ Rp. 9.200.000

Untuk perhitungan penambahan jam kerja (lembur) didasarkan pada UndangUndang No.13 Tahun 2003 tentang Ketenagakerjaan dan Kepmenakertrans No. 102/MEN/VI/2004 mengenai waktu dan upah kerja lembur.

Untuk pekerjaan galian pondasi lembur dilakukan selama 1 jam setiap hari perhitungannya sebagai berikut.

Upah harian Mandor $=$ Rp. 120.000

Upah Harian Pekerja $=$ Rp. 80.000

Waktu kerja sehari $=8 \mathrm{jam} / \mathrm{hari}$

Selanjutnya dihitung upah perbulan dan upah perjam sesuai peraturan Menteri, untuk waktu kerja 8 jam/hari upah perhari dikalikan 25 dan untuk upah perjam, upah perbulan dikalikan 1/173 kemudian upah perjam dikalikan 1,5 untuk 1 jam pertama dan dikalikan 2 untuk 2 jam dan seterusnya.

Upah perbulan Mandor : $25 \times$ Rp. $120.000=$ Rp. 3.000 .000

Upah perbulan Pekerja : $25 \times$ Rp. $80.000=$ Rp 2.000 .000

Upah per jam Mandor : $\operatorname{Rp} 3.000 .000 \times \frac{1}{173}=\mathrm{Rp} .17 .341$

Upah per jam Pekerja : Rp. $2.000 .000 \times \frac{1}{173}=$ Rp. 11.561

Jadi Upah pekerja untuk 1 jam lembur adalah:

Mandor : 1,5 x Rp. $17.341 \times 2$ orang = Rp. 52.023

Pekerja : 1,5 x Rp. $11.561 \times 20$ orang = Rp. 346.281

Total upah lembur selama 5 hari : (Rp.52.023 + Rp. 346.281) x $5=$ Rp. 1.994 .220

Total upah selama 5 hari adalah:

Rp. 9.200.000 + Rp. 1.994.220 = Rp. 11.194.220

Selanjutnya perhitungan Slope biaya akibat percepatan adalah:

$$
\begin{aligned}
\text { Slope biaya } & =\frac{\text { Biaya dipersingkat }- \text { Biaya normal }}{\text { Waktu normal-Waktu dipersingkat }} \\
& =\frac{\text { Rp.11.194.220 }- \text { Rp. } 9.520 .000}{7-2} \\
& =\text { Rp. } 837.770 \text { perhari }
\end{aligned}
$$


Jadi kenaikan biaya selama 2 hari adalah Rp. 1.674 .220

Perhitungan crash program pekerjaan galian tanah dapat dilihat dalam Tabel 2, untuk memudahkan perhitungan trial and eror durasi pekerjaan digunakan aplikasi MS. Excel.

Tabel 2. Perhitungan Crash Program Pekerjaan Galian Tanah

\begin{tabular}{|c|c|r|r|c|}
\hline $\begin{array}{c}\text { Uraian } \\
\text { Kegiatan }\end{array}$ & Durasi & \multicolumn{1}{|c|}{ Total Biaya } & Cost Slope & $\begin{array}{c}\text { Biaya } \\
\text { Percepatan }\end{array}$ \\
\hline Normal & 7 & Rp. 9.520.000 & & - \\
\hline Crash 1 & 6 & Rp. 9.600.000 & Rp. 80.000 & Rp. 80.000 \\
\hline Crash 2 & 5 & Rp. 11.194.220 & Rp. 837.110 & Rp. 1.674.220 \\
\hline Crash 3 & 4 & Rp. 14.214.566 & Rp. 1.564.855 & Rp. 4.694.566 \\
\hline Crash 4 & 3 & Rp. 14.094.104 & Rp. 1.143.526 & Rp. 4.574.104 \\
\hline
\end{tabular}

\section{Pekerjaan Pasangan Pondasi Batu Kali/ Belah}

Perhitungan crash program pekerjaan pasangan pondasi batu kali/belah dapat dilihat dalam Tabel 3.

Tabel 3. Perhitungan Crash Program pekerjaan pasangan pondasi batu kali/belah

\begin{tabular}{|c|c|c|c|c|}
\hline $\begin{array}{c}\text { Uraian } \\
\text { Kegiatan }\end{array}$ & Durasi & Total Biaya & Cost Slope & $\begin{array}{c}\text { Biaya } \\
\text { Percepatan }\end{array}$ \\
\hline Normal & 10 & Rp. 26.600 .000 & & - \\
\hline Crash 1 & 9 & Rp. 26.460 .000 & Rp. 860.000 & Rp. 860.000 \\
\hline Crash 2 & 8 & Rp. 26.240 .000 & Rp. 320.000 & Rp. 640.000 \\
\hline Crash 3 & 7 & Rp. 26.180 .000 & Rp. 193.333 & Rp. 580.000 \\
\hline Crash 4 & 6 & Rp. 26.040 .000 & Rp. 110.000 & Rp. 440.000 \\
\hline
\end{tabular}

\section{Pekerjaan Plesteran Dinding Bata}

Perhitungan crash program pekerjaan Plesteran Dinding Bata dapat dilihat dalam Tabel 4.

Tabel 4. Perhitungan crash Program pekerjaan plesteran dinding

\begin{tabular}{|c|c|c|c|c|}
\hline $\begin{array}{c}\text { Uraian } \\
\text { Kegiatan }\end{array}$ & Durasi & Total Biaya & Cost Slope & $\begin{array}{c}\text { Biaya } \\
\text { Percepatan }\end{array}$ \\
\hline Normal & 10 & Rp. 28.400 .000 & - & - \\
\hline Crash 1 & 9 & Rp. 33.071.618 & Rp. 4.617.618 & Rp. 4.671.618 \\
\hline Crash 2 & 8 & Rp. 34.512.370 & Rp. 3.056.185 & Rp. 6.112.370 \\
\hline Crash 3 & 7 & Rp. 34.316.994 & Rp. 1.972.331 & Rp. 5.916.994 \\
\hline Crash 4 & 6 & Rp. 34.070.983 & Rp. 1.417.746 & Rp. 5.670.983 \\
\hline
\end{tabular}

\section{Pekerjaan Rangka Plafond Baja Ringan}

Perhitungan crash program pekerjaan rangka plafond baja ringan dapat dilihat dalam Tabel 5. 
Tabel 5. Perhitungan crash program pekerjaan rangka plafond baja ringan.

\begin{tabular}{|c|c|r|r|r|}
\hline Uraian Kegiatan & Durasi & \multicolumn{1}{|c|}{ Total Biaya } & \multicolumn{1}{c|}{ Cost Slope } & Biaya Percepatan \\
\hline Normal & 7 & Rp. 3.640 .000 & - & - \\
\hline Crash 1 & 6 & Rp. 4.920 .000 & Rp. 1.280 .000 & Rp. 1.280 .000 \\
\hline Crash 2 & 5 & Rp. 4.500 .000 & Rp. 430.000 & Rp. 860.000 \\
\hline Crash 3 & 4 & Rp. 3.920 .000 & Rp. 93.333 & Rp. 280.000 \\
\hline Crash 4 & 3 & Rp. 4.320 .000 & Rp. 170.000 & Rp. 680.000 \\
\hline
\end{tabular}

\section{Pekerjaan Plafond Gypsum}

Perhitungan crash program pekerjaan plafond gypsum dapat dilihat dalam Tabel6.

\begin{tabular}{|c|c|r|r|r|}
\hline $\begin{array}{c}\text { Uraian } \\
\text { Kegiatan }\end{array}$ & Durasi & \multicolumn{1}{c|}{ Total Biaya } & Cost Slope & $\begin{array}{c}\text { Biaya } \\
\text { Percepatan }\end{array}$ \\
\hline Normal & 7 & Rp. 8.960.000 & - & - \\
\hline Crash 1 & 6 & Rp. 10.568.844 & Rp. 1.698.844 & Rp. 1.698.844 \\
\hline Crash 2 & 5 & Rp. 10.564.162 & Rp. 752.081 & Rp. 1.504.162 \\
\hline Crash 3 & 4 & Rp. 9.636.763 & Rp. 225.558 & Rp. 676.763 \\
\hline Crash 4 & 3 & Rp. 11.654.740 & Rp. 673.685 & Rp. 2.694.740 \\
\hline
\end{tabular}

\section{Pekerjaan Lantai Keramik}

Perhitungan crash program pekerjaan lantai keramik dapat dilihat dalam Tabel 7 .

Tabel 7. Perhitungan Crash Program pekerjaan lantai keramik.

\begin{tabular}{|c|c|r|r|r|}
\hline $\begin{array}{c}\text { Uraian } \\
\text { Kegiatan }\end{array}$ & Durasi & \multicolumn{1}{|c|}{ Total Biaya } & \multicolumn{1}{c|}{ Cost Slope } & $\begin{array}{c}\text { Biaya } \\
\text { Percepatan }\end{array}$ \\
\hline Normal & 5 & Rp. 13.800.000 & - & - \\
\hline Crash 1 & 4 & Rp. 13.920.000 & Rp. 120.000 & Rp. 120.000 \\
\hline Crash 2 & 3 & Rp. 13.920.000 & Rp. 60.000 & Rp. 120.000 \\
\hline Crash 3 & 2 & Rp. 16.693.988 & Rp. 954.663 & Rp. 2.893.988 \\
\hline Crash 4 & 1 & Rp. 16.304.624 & Rp. 626.156 & Rp. 2.504.624 \\
\hline
\end{tabular}

Setelah perhitungan crash program masing-masing pekerjaan, selanjutnya perhitungan biaya langsung akibat percepatan durasi. Perhitungannya dapat dilihat pada tabel 8.

Tabel 8. Perhitungan Biaya Langsung Akibat Percepatan

\begin{tabular}{|c|c|c|c|c|}
\hline $\begin{array}{c}\text { Uraian } \\
\text { Kegiatan }\end{array}$ & $\begin{array}{c}\text { Durasi } \\
\text { Percepatan }\end{array}$ & Durasi Proyek & $\begin{array}{c}\text { Biaya } \\
\text { Percepatan }\end{array}$ & Biaya Langsung \\
\hline Normal & - & 180 & - & Rp. 1.411.755.509 \\
\hline Crash 1 & 6 & 174 & Rp. 8.710.462 & Rp. 1.420.465.971 \\
\hline Crash 2 & 12 & 168 & Rp. 10.910.751 & Rp. 1.431.376.723 \\
\hline Crash 3 & 18 & 162 & Rp. 15.042.312 & Rp. 1.446.419.305 \\
\hline Crash 4 & 24 & 156 & Rp. 16.564.451 & Rp. 1.462.983.486 \\
\hline
\end{tabular}

Berdasarkan hasil analisis pada Tabel 8 diatas dapat disimpulkan berdasarkan teori untuk perhitungan biaya langsung bahwa semakin dipercepat durasi pekerjaan, maka biaya langsung proyek akan naik seiring dengan durasi percepatan yang dilakukan. 


\section{3). Perhitungan Biaya Tidak Langsung}

Adapun rincian biaya tidak langsung (indirect cost) proyek pembangunan Gedung Peternakan Bone Bolango dapat dilihat pada Tabel 9.

Tabel 9. Perhitungan Biaya Tidak Langsung.

\begin{tabular}{|c|l|c|r|}
\hline No & \multicolumn{1}{|c|}{ Uraian } & Jumlah & Biaya Perbulan \\
\hline I & PELAKSANA & & \\
\hline 1 & Project Manager & & Rp. 9.170 .000 \\
\hline 2 & Logistik & 1 & Rp. 2.000 .000 \\
\hline 3 & Administrasi & 1 & Rp. 2.000 .000 \\
\hline 4 & Pengawas Lapangan & 2 & Rp. 3.000 .000 \\
\hline II & FASILITAS & & \\
\hline 1 & Alat Komunikasi & & Rp. 3.400 .000 \\
\hline 2 & Transportasi & & Rp. 1.200 .000 \\
\hline 3 & Listrik & & Rp. 2.500 .000 \\
\hline 4 & Air Kerja & & Rp. 1.500 .000 \\
\hline III & KEAMANAN & & \\
\hline 1 & Asuransi & & Rp. 2.100 .000 \\
\hline 2 & Security & 1 & Rp. 2.000 .000 \\
\hline 3 & Pembantu Umum 2.000 .000 \\
\hline \multicolumn{2}{|c|}{ Total } & & Rp. 30.870 .000 \\
\hline
\end{tabular}

Sumber: CV. Takabeya Konstruksi (2015).

Berdasarkan Tabel 9 diatas total biaya tidak langsung yang diperlukan selama sebulan sebesar Rp 30.870.000 sehingga total biaya tidak langsung yang akan dikeluarkan selama 180 hari kerja adalah sebagai berikut.

Total Biaya Tidak Langsung $=\frac{\text { Total Gaji perbulan }}{30 \text { hari }(\mathrm{ml} \mathrm{hr} \mathrm{dalam} 1 \mathrm{bln})} \times 180 \mathrm{HK}$

$$
\begin{aligned}
& =\frac{\text { Rp. } 30.870 .000,00}{30} \times 180 \mathrm{HK} \\
& =\operatorname{Rp} 185.220 .000
\end{aligned}
$$

Selanjutnya dihitung biaya gaji perhari, total biaya gaji dan total biaya tidak langsung

Biaya Gaji Perhari $=$ Total Biaya Tidak Langsung $\div$ Umur Proyek

$$
=\text { Rp. } 185.220 .000 \div 180 \mathrm{HK}
$$$$
=\operatorname{Rp} 1.029 .000 \text { perhari }
$$

Total Biaya Gaji = Biaya Gaji perhari $\times$ Waktu Percepatan

$$
\begin{aligned}
& =\operatorname{Rp} 1.029 .000 \times 6 \text { hari } \\
& =\operatorname{Rp} 6.174 .000
\end{aligned}
$$

Biaya Tidak Langsung $=$ Total Biaya Tidak Langsung - Total Biaya Gaji

$$
\begin{aligned}
& =\operatorname{Rp} 185.220 .000-\operatorname{Rp} 6.174 .000 \\
& =\operatorname{Rp} 179.046 .000
\end{aligned}
$$


Untuk lebih rinci perhitungan biaya tidak langsung disajikan pada tabel 10.

Tabel 10. Perhitungan Biaya Tidak Langsung.

\begin{tabular}{|c|c|c|c|c|}
\hline $\begin{array}{c}\text { Durasi } \\
\text { Proyek }\end{array}$ & $\begin{array}{c}\text { Biaya Gaji } \\
\text { Perhari }\end{array}$ & $\begin{array}{c}\text { Durasi } \\
\text { Percepatan }\end{array}$ & $\begin{array}{c}\text { Total Biaya } \\
\text { Gaji }\end{array}$ & $\begin{array}{c}\text { Total Biaya tidak } \\
\text { Langsung }\end{array}$ \\
\hline 180 & Rp. 1.029 .000 & - & Rp. 1.029 .000 & Rp. 185.220 .000 \\
\hline 174 & Rp. 1.029 .000 & 6 & Rp. 6.174 .000 & Rp. 179.046 .000 \\
\hline 168 & Rp. 1.029 .000 & 12 & Rp. 12.348 .000 & Rp. 172.872 .000 \\
\hline 162 & Rp. 1.029 .000 & 18 & Rp. 18.522 .000 & Rp. 166.698 .000 \\
\hline 156 & Rp. 1.029 .000 & 24 & Rp. 24.696 .000 & Rp. 160.524 .000 \\
\hline
\end{tabular}

Setelah didapatkan perhitungan biaya tidak langsung selanjutnya ditambahkan dengan biaya langsung untuk mendapatkan total biaya proyek Perhitungannya disajikan dalam tabel 11.

Tabel 11. Tabel total biaya proyek berdasarkan percepatan.

\begin{tabular}{|c|c|r|r|}
\hline \multirow{2}{*}{$\begin{array}{c}\text { Durasi } \\
\text { Proyek }\end{array}$} & \multicolumn{2}{|c|}{ Biaya Proyek } & \multirow{2}{*}{ Total Biaya Proyek } \\
\cline { 2 - 3 } & Biaya Langsung & Biaya Tidak Langsung & \\
\hline 180 & Rp. 1.411 .755 .509 & Rp. 185.220 .000 & Rp. 1.596.975.509 \\
\hline 174 & Rp. 1.420 .465 .971 & Rp. 179.046 .000 & Rp. 1.599.511.971 \\
\hline 168 & Rp. 1.431 .376 .723 & Rp. 172.872 .000 & Rp. 1.604.248.723 \\
\hline 162 & Rp. 1.446 .419 .035 & Rp. 166.698 .000 & Rp. 1.613.117.035 \\
\hline 156 & Rp. 1.462.983.486 & Rp. 160.524 .000 & Rp. 1.623.507.486 \\
\hline
\end{tabular}

Berdasarkan tabel 11 semakin dipercepat pelaksanaan proyek maka semakin besar pula biaya yang dibutuhkan, untuk biaya yang optimal diambil total biaya proyek sebesar Rp1.604.248.723 dengan umur proyek selama 168 hari.

Selanjutnya data biaya langsung akibat percepatan, biaya tidak langsung dan total biaya proyek disajikan dalam grafik-grafik berikut.

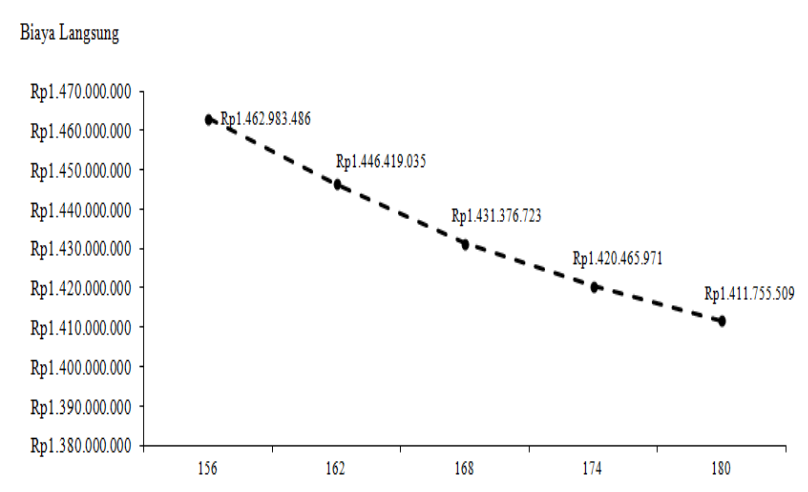

Gambar 1. Grafik Biaya Langsung Akibat Percepatan. 


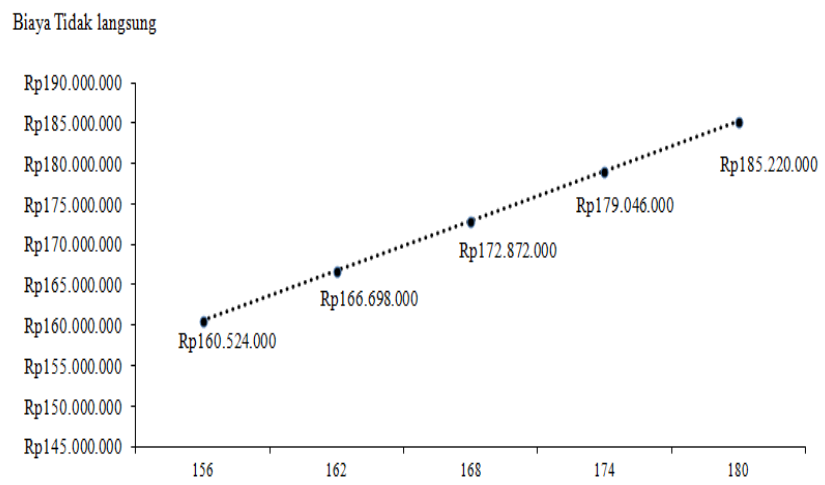

Gambar 2. Grafik Biaya Tidak Langsung Terhadap Waktu.

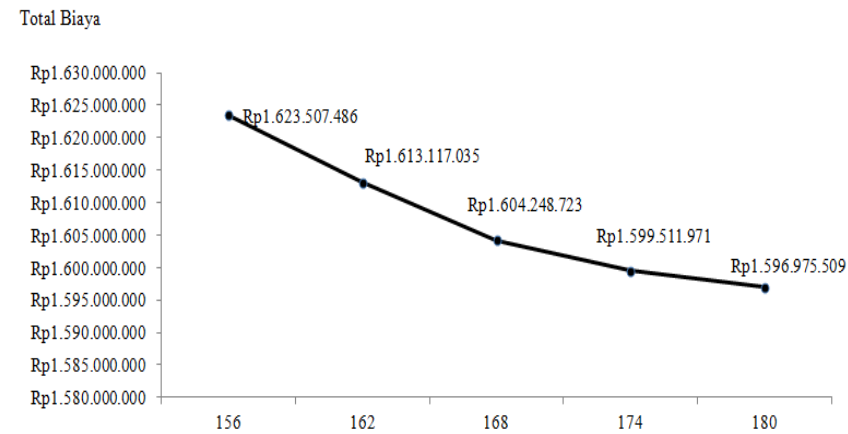

Gambar 3. Grafik Total Biaya Proyek Terhadap Waktu.

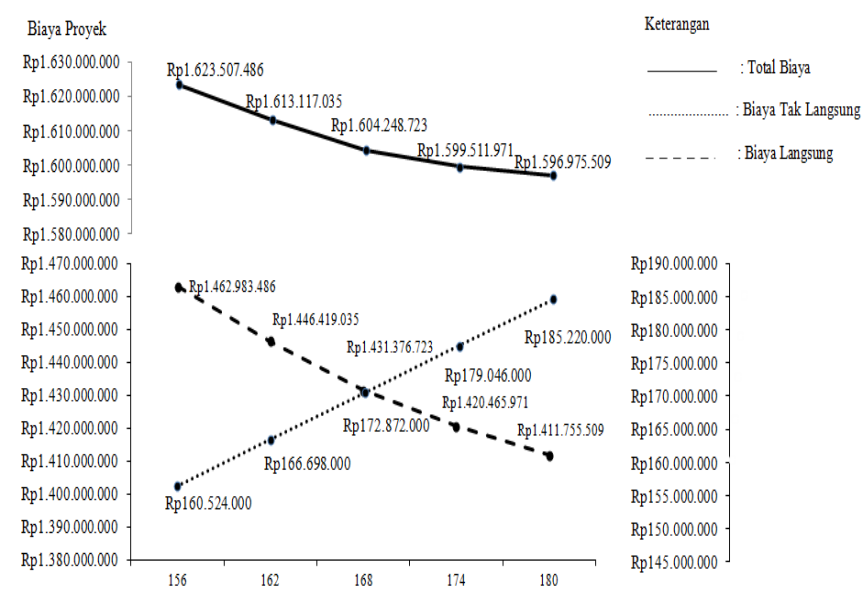

Gambar 4. Grafik Hubungan Biaya Langsung, Biaya Tidak Langsung dan Total Biaya

Proyek.

\section{Kesimpulan}

Berdasarkan penelitian dan hasil analisis yang dilakukan maka dapat diambil beberapa kesimpulan sebagai berikut.

1. Bentuk dari jaringan kerja (network planning) dengan menggunakan metode jalur kritis CPM (Critical Path Method) dapat dilihat pada lampiran yakni dengan durasi 180 hari kerja. Adapun kegiatan kritis yang dihasilkan oleh network planning adalah kegiatan A, B, C, D, E, F, L, M, N, O, P, Q, R, S, V, W, X, Y,Z, AA, AC, 
$A D, A F, A G, A H, A I, A J, A K, A L, A W, A X, A Y, A Z, B E, B F, B G, B H, B I, B J$ dan BK.

2. Durasi optimal proyek pembangunan gedung kantor Dinas Peternakan Kabupaten Bone Bolango diperoleh 168 Hari kerja karena biaya proyek mulai naik ketika durasi proyek semakin dikurangi. Terjadi pengurangan hari sebanyak 12 hari kerja dari durasi normal 180 hari kerja. Efisiensi waktu proyek sebesar $\frac{12}{180}$ $x 100 \%=6,67 \%$

3. Biaya Optimal proyek pembangunan gedung Kantor Dinas Peternakan Kabupaten Bone Bolango ditentukan sebesar Rp 1.604.248.723 terjadi kenaikan biaya sebesar Rp. 7.273.214.

\section{Daftar Pustaka}

Antu, Syafri, 2013, Optimalisasi Pelaksanaan Proyek Dengan Metode Jaringan Kerja PDM (Studi Kasus Proyek Pembangunan Gedung Pusat Layanan Administrasi Terpadu Universitas Negeri Gorontalo), Skripsi, Jurusan Teknik sipil, Fakultas Teknik, Universitas Negeri Gorontalo, Gorontalo.

Harahap, Rere, 2013, Cara Perhitungan Upah Kerja Lembur, https://rageofangel.wordpress.com/2013/05/01/cara-perhitungan-upah-kerjalemburl, 2 Februari 2016

Husen, Abrar, 2011, Manajemen Proyek : Perencanaan, Penjadwalan, \& Pengendalian Proyek, Edisi 1, Penerbit Andi, Yogyakarta.

Kurniawan, A. Saputra, R.A., 2012, Penerapan Metode Least Cost Analysis Pada Perencanaan Pembangunan Gedung Administrasi Dan Sentra Diklat Kia-Kb Balai Besar Pelatihan Kesehatan Makassar, Tugas Akhir, Jurusan Teknik Sipil, Fakultas Teknik, Universitas Muslim Indonesia, Makassar.

Soeharto, Iman, 1999, Manajemen Proyek : Dari Konseptual Sampai Operasional, Edisi 2, Erlangga, Jakarta.

Yuliati, Latief, H, 2005, Optimalisasi Biaya Dan Waktu Pelaksanaan Pada Proyek Pembangunan Gedung Student Center Fakultas Kedokteran Unhas, Tugas Akhir, Jurusan Teknik Sipil, Fakultas Teknik, Universitas Muslim Indonesia, Makassar. 